\title{
CONFORTO TÉRMICO DE VACAS LEITEIRAS NA AMAZÔNIA - REVISÃO DE LITERATURA
}

\author{
Jamires Silva de Souza ${ }^{1}$ \\ Maria Luiza Costa Castro ${ }^{2}$ \\ Marcio Gregório Rojas dos Santos ${ }^{3}$ \\ Maria das Dores Silva Araújo ${ }^{4}$ \\ Jomel Francisco dos Santos ${ }^{5}$
}

SOUZA, J. S. de; CASTRO, M. L. C.; SANTOS, M. G. R. dos; ARAÚJO, M. D. S.; SANTOS, J. F. dos. Conforto térmico de vacas leiteiras na Amazônia - revisão de literatura. Arquivos de Ciências Veterinárias e Zoologia da UNIPAR, Umuarama, v. 24, n. 2cont., e2406, 2021.

RESUMO: O estresse térmico é um dos principais problemas relacionados ao decréscimo do bem-estar animal em vacas leiteiras. Entre as regiões do Brasil, a Amazônia se destaca em suas características climáticas como os altos índices de temperatura e umidade atmosférica oriundos de uma região de clima equatorial. Nesse cenário, o estresse térmico é um dos fatores que prejudicam a criação, a produtividade, os parâmetros fisiológicos e o comportamento dos animais. Nesse sentido, o presente artigo de revisão visa contextualizar as características regionais com a produção leiteira na Amazônia, destacando o estresse térmico, seus efeitos e as estratégias de conforto térmico. Dessa forma, o emprego de medidas como o melhoramento genético, adoção de sistemas de produção silvipastoris e implantação de tecnologias são maneiras eficazes de melhoria das condições climáticas para os animais. No entanto, salienta-se a importância da realização de estudos específicos para determinação dos parâmetros de conforto térmico das vacas leiteiras na Amazônia.

PALAVRAS-CHAVE: Produção de leiteira. Amazônia. Estresse térmico. Conforto.

\section{THERMAL COMFORT OF DAIRY COWS IN THE AMAZON - LITERATURE REVIEW}

\begin{abstract}
Heat stress is an important issue related to decrease in animal welfare in dairy cows. The Amazon region stands out in Brazil due to its diverse climatic characteristics, with high temperature and atmospheric humidity resulting from its equatorial climate. In this context, heat stress is one of the factors that impair the breeding, productivity, physiological parameters, and behavior of those animals. This article aims at performing a literature review in order to contextualize the regional characteristics with dairy production in the Amazon, with focus on heat stress, its effects, and thermal comfort strategies. The use of measures such as genetic improvement, adoption of production using silvopastoral system and the implementation of technologies are effective ways to improve climatic conditions for animals. However, the importance of conducting specific studies to determine the parameters of thermal comfort of dairy cows in the Amazon is also emphasized.
\end{abstract}

KEY WORDS: Amazon. Comfort. Dairy production. Heat stress.

\section{CONFORT TÉRMICO DE VACAS LECHERAS EN AMAZONÍA - REVISIÓN DE LITERATURA}

RESUMEN: El estrés por calor es uno de los principales problemas relacionados con la disminución del bienestar animal en vacas lecheras. Entre las regiones de Brasil, la Amazonia se destaca por sus características climáticas, como los altos niveles de temperatura y humedad atmosférica que surgen de una región con clima ecuatorial. En este escenario, el estrés por calor es uno de los factores que inciden en la creación, productividad, parámetros fisiológicos y comportamiento de los animales. Este artículo de revisión tuvo como objetivo contextualizar las características regionales de la producción lechera en Amazonía, destacando el estrés térmico, sus efectos y estrategias de confort térmico. Así, el uso de medidas como el mejoramiento genético, la adopción de sistemas de producción silvopastoril y la implementación de tecnologías son formas efectivas de mejorar las

DOI: $10.25110 /$ arqvet.v24i2cont.2021.8717

${ }^{1}$ Técnica de campo do Serviço Nacional de Aprendizagem Rural do Amazonas (SENAR AM), Amazonas.

2 Graduanda em Medicina Veterinária pelo Instituto Federal de Educação, Ciência e Tecnologia do Amazonas, Brasil.

${ }^{3}$ Instrutor do Serviço Nacional de Aprendizagem Rural de Rondônia (SENAR RO), Rondônia.

${ }^{4}$ Zootecnista, Doutora em Ciência Animal Tropical (UFRPE), Recife.

${ }^{5}$ Professor do Curso de Medicina Veterinária. Instituto Federal de Educação, Ciência e Tecnologia do Amazonas, Brasil, 
condiciones climáticas para los animales. Sin embargo, se destaca la importancia de realizar estudios específicos para determinar los parámetros de confort térmico de las vacas lecheras en Amazonía.

PALABRAS CLAVE: Producción de leche. Amazonia. Estrés térmico. Confort.

\section{Introdução}

A produção leiteira é uma atividade exercida mundialmente, de importância econômica, social e de valor nutritivo agregado ao produto (VILELA, 2016). Segundo dados da Food and Agriculture Organization of the United Nations (2019) foram produzidos 883 milhões de toneladas de leite mundialmente no ano de 2019, sendo o Brasil o terceiro maior produtor com o volume de 34 bilhões de litros (IBGE, 2019a), gerando o valor bruto de 43 bilhões de reais (BRASIL, 2019).

Geograficamente, as altas taxas de produção ficam concentradas nas regiões sul e sudeste, em contrapartida, nas regiões Norte, Nordeste e Centro-Oeste apesar dos menores números na produção, possuem as maiores taxas de crescimento (IBGE, 2019).

Nesse cenário está incluso a Amazônia, com produção anual de dois bilhões de litros de leite (IBGE, 2019b). É uma região com características climáticas equatoriais e com elevados índices de temperatura e umidade (IBGE, 2002). Consequentemente, na criação regional de vacas leiteiras há influência do estresse térmico, levando a alterações comportamentais e fisiológicas, diminuição na qualidade do leite e com isso perdas econômicas (DALTRO et al., 2020).

Desse modo, para a produção de leite na Amazônia, é necessário o planejamento de estratégias de manejo visando diminuir os efeitos deletérios do estresse calórico aos animais, por meio da adoção de medidas como o cruzamento entre raças de alta produtividade com animais mais adaptados aos climas tropicais, estratégias de condicionamento térmico passivo através de sombreamento (natural ou artificial), ventilação e refrigeração. Do mesmo modo, os modelos de sistemas sustentáveis de produção pecuária e arborização de pastagens, tais como a integração Lavoura-Pecuária-Floresta (ILPF), e o sistema silvipastoril com pastejo rotacional (SSPR), se mostram muito eficientes, pois além de proverem sombra aos animais, exercem múltiplas funções dentro do sistema (PINHEIRO, 2012; PINHEIRO, 2015; SILVA, 2018).

Diante do exposto, este trabalho teve como objetivo trazer um panorama do estresse térmico na produção de vacas leiteiras na Amazônia, visando às técnicas de melhoria do conforto térmico que podem ser aplicadas na região, considerando artigos publicados nos últimos 20 anos.

Para a escrita deste artigo, executou-se uma revisão de literatura, utilizando como base artigos científicos publicados no Brasil e em outros países, em idiomas português e inglês, e livros do período de 2000 a 2020 . Envolveu cinco pesquisadores no período de março a junho de 2021, aplicando no critério de seleção e análise dos artigos a relevância, data de publicação e aplicação técnica. Considerando os marcadores: produção leiteira, vaca leiteira, estresse térmico, conforto térmico e Amazônia. Foram pesquisados nas principais bases de dados acadêmicas e de pesquisa: EMBRAPA, Google Acadêmico,
Scholar, Scielo, ScienceDirect, SIDRA IBGE.

\section{Desenvolvimento}

\section{Características da Amazônia}

O território Amazônico coincidindo com a floresta amazônica, é representado no país pela porção norte, o qual possui características climáticas marcantes influenciadas pela localização na faixa equatorial, conferindo a denominação de clima equatorial, com índices elevados de temperatura e umidade atmosférica, tendo média de 24 a $26^{\circ} \mathrm{C}$ e com regiões em que a temperatura chega aos $40^{\circ} \mathrm{C}$. Devido à extensão do território, há mudanças regionais neste clima, subdividindo-se na região extremo oeste da Amazônia em clima equatorial seco ou superúmido, em que todo o ano prevalecem temperatura e umidade elevadas. $\mathrm{Na}$ porção centro-oeste dos estados do Amazonas e Acre, sudoeste de Roraima e nordeste do Amapá e Pará, prevalece o clima equatorial com subseca, apresentando altas temperaturas ao longo do ano com um a dois meses de subseca. Por fim, o clima equatorial com subseca de três meses, em que se mantêm os altos índices de temperatura e umidade, mas os pluviométricos reduzem por um período de três meses, ocorrendo nas regiões de fronteira do domínio climático de equatorial para tropical do Brasil central (MENDONÇA, 2007).

A umidade relativa (UR) do ar na região é alta, Orellana et al. (2020) mensuraram as variáveis de UR em diversos locais na Amazônia, obtendo os valores no estado do Amapá variando de $67 \%$ a $85 \%$; em Rio Branco - AC variou entre $77 \%$ a 91\%; em Presidente Figueiredo - AM mensurou $85 \%$ e em Belém - PA foi de $86 \%$, representando as condições de clima quente e chuvoso da região.

Seguindo as características regionais, divide-se em duas principais estações, o inverno, delimitado pelo período de cheia dos rios e coincide com o período chuvoso, e o verão no qual há um decréscimo no nível dos rios, mas com continuidade da precipitação, tendo chuvas de verão austral (de janeiro a março) no sul da Amazônia, e chuvas com maiores precipitações no verão boreal no norte da região (de maio a julho), de acordo com Ab'Sáber, (2003).

\section{Produção leiteira na Amazônia}

A produção leiteira iniciou com a introdução dos primeiros bovinos na Amazônia, na qual devido à proximidade com Portugal, as primeiras criações de gado foram na ilha de Joanes, atual Marajó. Outros registros da entrada dos bovinos na região citam a cidade de Belém, com gado originário da Península Ibérica predominantemente de bovinos crioulos (gado "nacional", "comum", "curraleiro" e "pé duro"). Favorecendo a ocupação e povoamento territorial nos interiores, enquanto contribuía no transporte e na oferta de leite, carne e couro (DIAS-FILHO, 2020; SALMAN; PFEIFER, 2020; 


\section{SIMONSEN, 2005).}

Atualmente, a Amazônia representada pela região norte, produz dois bilhões de litros de leite anuais, destacandose nos estados de Rondônia e Pará. Apesar da diferença numérica da região em comparação a outras regiões do país, no local houve expressivo aumento na taxa de crescimento que foi de 22\% comparando o ano de 2015 para 2019 (IBGE, 2019).

Segundo o último censo agropecuário realizado no ano de 2017, na região Norte foram 1.900 bilhões de litros de leite produzidos por 1.392.301 vacas ordenhadas (IBGE, 2017), com valores individuais estaduais na Tabela 1 , repercutindo a baixa produtividade local que se associa à gradativa e lenta incorporação de tecnologias ao setor agropecuário, com exceção de Rondônia, que detém melhor produtividade (SALMAN; PFEIFER, 2020).

Figura 1: Contraste da produção de leite bovino pelo efetivo do rebanho na região norte do Brasil

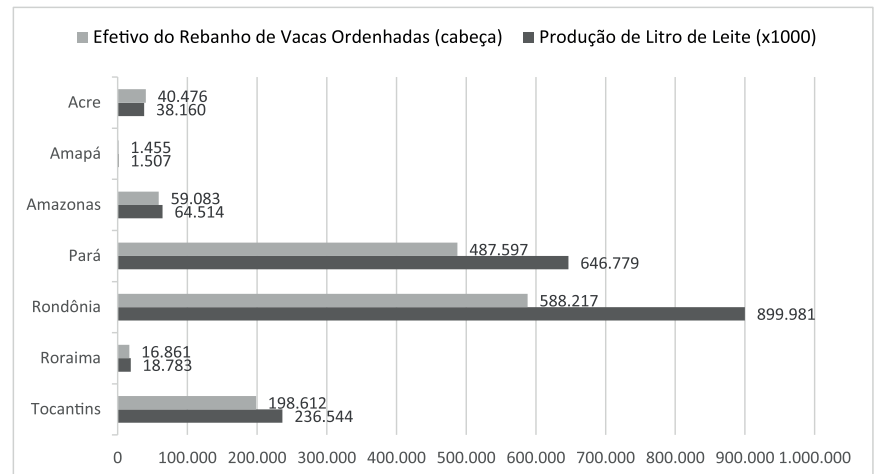

Fonte: Censo Agropecuário 2017 (IBGE).

Ainda com informações sobre o censo, como maior produtor regional, Rondônia apresentou $80 \%$ dos produtores rurais (217.757 pessoas) que possuíam laço de parentesco com o produtor, refletindo em uma produção predominantemente de base familiar (IBGE, 2017). Sobre os dados da tecnologia na pecuária de leite, Pereira et al. (2019) evidenciaram que no município de Presidente Figueiredo - AM, 57,4\% dos produtores realizam uma ordenha diária. Em relação ao uso de ordenha mecanizada, em Tocantins, observou-se que apenas $1,3 \%$ dos estabelecimentos daquela região produzem leite utilizando ordenha mecânica, enquanto em Rondônia, 1,59\% dos estabelecimentos fazem uso da ordenha mecanizada (SANTOS et al., 2011; 2014).

Herrera Mast (2006), a partir de estudo em unidades de produção na região de Manaus, Manacapuru, Itacoatiara e Careiro da Várzea, utilizando a classificação de Only \& Hund (1996), caracterizou a produção Amazônica de bovinos com predominância do sistema de criação extensivo e semiintensivo.

Destacando no semi-intensivo a produção leiteira em propriedades que utilizam o plantel para venda de leite e de animais terminados (dupla aptidão), com piquetes rotacionados, adubação, suplementação alimentar proteica e energética com uso de sal mineralizado, seguido de propriedades em que há suplementação alimentar adicional à base de capineiras, e por fim em propriedades com uso de mão-de-obra especializada, pastagens fertilizadas, registros zootécnicos e uso de biotecnologias para melhoramento genético, porém com o baixo índice de animais por território, de 1,11UA/ha em média (HERRERA MAST, 2006).

Enquanto no sistema extensivo, utilizado principalmente nas áreas de várzea, com 1,33UA/ha, destacase o sistema de cria e recria na qual os animais são deslocados para áreas altas ou utilizam-se marombas no período das cheias, e para terras mais baixas no período de vazantes, tirando proveito do crescimento natural da vegetação no período, sendo utilizado para o gado de corte com expressão de dupla aptidão, onde a produção de leite é baixa ou visada principalmente para o consumo próprio dos produtores (HERRERA MAST, 2006).

\section{Efeitos do estresse térmico}

A produção leiteira está intimamente ligada à manutenção do animal na zona de termoneutralidade. Essa por sua vez, trata-se de um intervalo de temperatura onde o animal não sofre estresse pelo frio ou calor. Não há consenso quanto à delimitação da faixa de conforto térmico, pois é dependente das variáveis da UR e a adaptação do animal. Resultados preliminares de Yousef e Roenfeldt $(1985 ; 1998)$ descrevem a zona de termoneutralidade em bovinos de $5^{\circ}$ a $25^{\circ} \mathrm{C}$, sendo essa modificada quanto à raça, categoria animal, características climáticas, nutrição, sistemas de produção, entre outros (AZEVEDO et al, 2001; DALCIN, 2013; MARTELLO, 2006).

Os animais homeotérmicos mantêm sua temperatura corporal a partir do equilíbrio termorregulatório entre animal e ambiente. Esses mecanismos resultam em elevação da taxa metabólica, que por sua vez eleva ainda mais a produção de calor, que se não dissipado, aumenta a temperatura corporal até níveis perigosos (CUNNINGHAM, 2004).

$\mathrm{Na}$ produção animal voltada para a pecuária leiteira, é imprescindível a adoção de um sistema de produção que garanta o bem estar animal, que de acordo com o relatório do Comitê Brambell, no aspecto das cinco liberdades animal, define-se em livre de sede, fome e desnutrição, livre de desconforto, livre de dor, injúrias e doenças, livres de medo e livres para expressarem os padrões normais de comportamento animal. O qual no contexto do conforto térmico deve-se proteger os animais de condições climáticas adversas e suas consequências, mudanças que causam estresse, sejam pelo calor ou frio (FAO; IDF, 2013).Característico da Amazônia, a elevação da temperatura põe o animal em frequente estimulação dos mecanismos termorregulatórios, visto que o clima tropical excede a zona de termoneutralidade dos animais, esses expressam-se com respostas de mecanismos fisiológicos e mecanismos comportamentais, intervindo diretamente no bem-estar e na produtividade (BATISTA et al., 2015; FIGUEIREDO et al, 2014).

Entre os mecanismos fisiológicos responsivos ao estresse por calor, Mynka e Ayo, (2010) apontaram como principal parâmetro a frequência respiratória (FR) e a temperatura retal (TR). Figueiredo et al. (2014) também citam como resposta a intensificação da sudorese, pois com o aumento da temperatura do organismo há o aumento da 
sudorese e da FR para eliminação do calor. Outra resposta observada é o acamamento dos pelos, que facilita a retirada do calor corporal através da diminuição da camada de ar existente entre o pelo e a pele do animal.

A água compõe 56 a $81 \%$ do peso corporal de uma vaca leiteira, onde sua totalidade corresponde a processos fisiológicos e metabólicos, como a excreção, transporte ou composição de nutrientes para as células, digestão e metabolismo de nutrientes, manutenção hidroeletrolítica, entre outros, sendo que alterações no volume de água até $20 \%$ podem levar o animal ao óbito (NCR, 2001).

Couto (2013), avaliou que vacas leiteiras submetidas a um ambiente sem sombreamento na região Amazônica tendem a apresentar alterações correlativas entre o aumento da TR e maior FR, na concentração plasmática de cortisol dos bovinos desse sistema as taxas foram maiores e no limite do valor de referência aceitável, conforme os parâmetros de Encarnação (1997), resultando na influência negativa na eficiência produtiva.

Nos mecanismos comportamentais de resposta ao calor, os bovinos modificam sua postura ao reduzir atividades como ingestão, digestão e absorção de alimentos, pois contribuem para a produção de calor corporal. Em contrapartida, expressam-se reduzindo a movimentação, prostrados, situados em locais de sombra e frescos, posicionados frente a correntes de vento e pastejando no início da manhã e fim da tarde quando a temperatura ambiente diminui (FIGUEIREDO et al. 2014).

\section{Estratégias para obtenção do conforto térmico}

Para minimizar os distúrbios causados em virtude do estresse calórico devem-se buscar medidas para nortear ações de manejo que visem reduzir os danos que esse pode causar (MINKA; AYO, 2010). O conjunto de características físicas como a topografia do terreno, características do solo e distribuição dos recursos naturais devem ser fatores decisivos para definir as construções da propriedade, visando às necessidades dos bovinos de recurso hídrico, sombra, acesso facilitado aos pastos e distância entre as estruturas (PARANHOS DA COSTA, 2000).

A partir da adoção de medidas corretivas ou auxiliares para evitar ou diminuir o estresse térmico das vacas no território amazônico, os animais apresentam maior ingestão de alimento e reduzem o tempo de ócio. De acordo com os resultados de Carvalho e Moraes (2005), as ações de manejo influenciam o padrão de comportamento ingestivo nos animais, tornando-o um fator estratégico na adequação dos animais ao ambiente no qual se encontram.

Os animais submetidos a um ambiente de pastejo favorável, o qual é estipulado por posturas comportamentais como a escolha de poucas estações alimentares com maior tempo explorando-as, tendem a realizar um maior número de refeições com menores durações, refletindo na maior velocidade de ingestão obtida em condições de elevado nível de alimentação (CARVALHO; MORAES, 2005).

A climatização no processo de bem-estar e produtividade animal é justificada pela garantia de melhores condições ao animal, que gera retorno com aumento na produção. Almeida (2010; 2013) observou que animais expostos a 30 minutos de climatização pelo sistema de resfriamento adiabático evaporativo, antes da ordenha indicaram comportamentos favoráveis ao bem-estar animal, refletindo em melhor condicionamento térmico, maior frequência de acesso ao comedouro, bebedouro e tempo de ruminação e principalmente, aumento de $45 \%$ na produção de leite. Isso possibilitou um melhor acondicionamento térmico resultando em queda na temperatura retal, frequência respiratória e temperatura do pelame. Adicionalmente, o uso de climatização permite que os animais se alimentem mesmo nas horas mais quentes do dia (VILELA, 2013).

Reforçando, Couto (2013) em Bujarú-PA, observou ao comparar as variáveis fisiológicas de vacas com ou sem sombreamento, que a FR, TR e temperatura de superfície corporal mantiveram-se próximas a normalidade nos animais com sombreamento.

$\mathrm{O}$ rápido diagnóstico frente às condições de estresse pode auxiliar o produtor na tomada de decisões para minimizar seus efeitos negativos, entre as medidas trata-se do acionamento de ventiladores e aspersores (MARTELLO, 2006).

A ingestão de água é importante devido a sua capacidade de remoção do calor desde que esteja em temperatura inferior a corporal. Foi constatado que um dos mecanismos para combater o excesso de temperatura, é o aumento na ingestão hídrica. Em seu estudo, Perissinoto (2005) observou que os animais dobraram a quantidade de agua ingerida em dias quentes, passando para 63,8L ingeridos, em contraste com 37,3L em dias com menores temperaturas. Sendo o maior momento de ingestão em dias e em horários mais quentes, e após a ordenha, relacionado à reposição e de acordo com o nível produtivo individual. Assim, a instalação de bebedouros a pasto, ofertando água de melhor qualidade, fresca e limpa, aparece como uma alternativa para a diminuição dos efeitos causados pelo estresse (TAVARES; BENEDETTI, 2011).

Outro método para minimizar o problema do estresse térmico em vacas leiteiras é por meio de estratégias de cruzamentos genéticos ou raças mais adequadas ao clima tropical. O gado leiteiro utilizado na Amazônia é de predominância mestiça, advindo de cruzamentos de bovinos de origem europeia (Bos taurus taurus) e origem indiana (Bos taurus indicus), destacando-se as raças Holandesa, Pardo Suíço, Gir e em menor número, Guzerá. Também é bastante influente a raça nacional Girolando (VEIGA, 2006).

Em condições climáticas mesotérmicas na região de Minas Gerais, vacas 1/2 Holandês-Zebu demonstraram maior tolerância ao calor do que as $7 / 8$, enquanto as $3 / 4$ se mantiveram em posição intermediária (AZEVEDO, 2005).

Analisando as raças bovinas naturalizadas brasileiras como o Curraleiro, Mocho Nacional, Crioulo Lageano, Pantaneira e Junqueira, frente às raças Nelore e Holandês, os resultados obtidos demonstraram que as raças Curraleiro e Junqueira são mais adaptadas ao calor (BIANCHINI et al., 2006).

Assim a melhor opção seria o cruzamento de uma raça com maior resistência ao calor com outra de alta produção. 
A utilização de animais adaptados, que apresentem uma alta produtividade também é de grande importância. Nesse sentido, recomenda-se a adoção de raças zebuínas no rebanho como o Gir e Guzerá ou raças nacionais como o Girolando, Pitangueiras, Curraleiro e Junqueira, uma vez que possuem grande potencial adaptativo e produtivo. Devido às condições climáticas observadas na Amazônia, torna-se inviável o melhoramento genético visando apenas a alta produtividade de raças europeias, de forma que para o desenvolvimento produtivo em regiões tropicais é necessário utilizar genótipos de acordo com os objetivos, utilizando raças nativas ou adaptadas, assegurando suas necessidades e possibilitando que demonstrem todo seu desempenho produtivo (FAÇANHA et al., 2013; VEIGA, 2006;).

Sobre os sistemas de manejo visando o conforto térmico, novilhas Girolando ( $3 / 4$ holândes e $1 / 4$ Gir) foram conduzidas a pastejo em piquetes rotacionados no sistema ILPF e LPF sombreado por árvores de eucalipto e apresentaram menor valor de temperatura interna em sistema ILPF, em comparação com sistema de integração ILP, o que resultou em maior tempo em pastejo e redução da temperatura interna das novilhas (VEIT, 2016). No entanto, Silva e Scwartz (2019) evidenciaram na região de Paragominas - Pará, que a planta mogno africano revelou-se mais promissora nas características Amazônicas, enquanto houve alta mortalidade do eucalipto em ILPF.

Salman et al. (2008) descreveram algumas espécies arbóreas com potencial, dentre elas o buriti, piquiá, cajámirim, castanha-do-brasil, visgueiro, cedro, garapa, paineira, jenipapo, jatobá, mamica-de-porca, paricá, parapará, sumaúma, ipê-amarelo e embaúba.

Quanto ao sistema de sombreamento artificial a pasto, foi constatado que em condições de estresse térmico, novilhas leiteiras mestiças mostraram a melhor área em $3 \mathrm{~m}^{2}$ de sombreamento por animal (MELLACE, 2009). Complementando, novilhas condicionadas ao sombreamento proporcionaram manutenção das variáveis fisiológicas próximas da normalidade, adicionadas ao aumento em $18 \%$ na porcentagem de prenhez e diminuição nos níveis de concentração de cortisol (COUTO, 2013).

\section{Consideraç̃̃es finais}

A pecuária leiteira é uma atividade em expansão e de importância socioeconômica para a Amazônia, no entanto, as características climáticas tropicais da região dificultam a criação de bovinos de leite satisfatoriamente no quesito de produção aliada ao bem-estar animal.

A adoção de práticas para o desenvolvimento produtivo aliado a melhorias nas condições ambientais visando o conforto térmico na região devem ser consideradas, sendo de suma importância a implementação do melhoramento genético com bovinos mestiços ou exemplares da espécie Bos taurus indicus com aptidão leiteira, devido a sua rusticidade, adaptação ao clima tropical e aos parasitas, associado à implantação de tecnologias de climatização como aspersores e sombreamento, além do incentivo a sistemas produtivos, como a integração lavoura e pecuária, como diversificação da produção e manutenção de uma pecuária sustentável.

Estudos atuais ainda não comprovam a utilização de estratégias de conforto térmico aplicado na Amazônia, salientando a importância de estudos mais específicos para definição de parâmetros de conforto térmico voltado à pecuária leiteira na região Amazônica.

\section{Referências}

AB'SÁBER, A. N. Os domínios de natureza no Brasil: potencialidades paisagísticas / Aziz Ab'Sáber. - São Paulo: Ateliê Editorial, 2003. 60p.

ALMEIDA, G. L. P. de et al. Investimento de climatização na pré-ordenha de vacas girolando e seus efeitos na produção de leite. Revista Brasileira de Engenharia Agrícola e Ambiental. Campina Grande, v.14, n. 12, 1337-1344p., Dec. 2010.

ALMEIDA, G. L. P. de et al. Comportamento, produção e qualidade do leite de vacas Holandês-Gir com climatização no curral. Revista Brasileira de Engenharia Agrícola e Ambiental. Campina Grande, v. 17, n. 8, 892-899p. 2013.

AZEVEDO et al. Estimativa de Níveis Críticos Superiores do Índice de Temperatura e Umidade paraVacas Leiteiras 1/2, 3/4 e 7/8 Holandês-Zebu em Lactação. Revista Brasileira de Zootecnia, v. 34, n. 6, p. 2000-2008, 2005.

BATISTA, J. N. et al. Termorregulação em ruminantes. Agropecuária Científica no Semi-Árido. v. 11, n. 2, p. 3946, abr-jun, 2015. DOI: 10.30969/acsa.v11i2.674.

BIANCHINI, E. et al. Características corporais associadas com a adaptação ao calor em bovinos naturalizados brasileiros. Pesquisa Agropecuária Brasileira. Brasília, v. 41, n. 9, p. 1443-1448, set. 2006.

BRASIL. Ministério da Agricultura, Pecuária e Abastecimento. Valor Bruto da Produção Agropecuária. Disponível em: https://www.gov.br/agricultura/pt-br/politicaagricola/valor-bruto-da-produção-agropeccuaria-vpb. Acesso em: 23 fev. 2021.

CARVAlHO, P. C. F.; MORAES, A. de. Comportamento ingestivo de Ruminantes: bases para o manejo sustentável do pasto. In: Ulysses Cecato; Clóves Cabreira Jobim. (Org.). Manejo Sustentável em Pastagem. Maringá-PR: UEM, 2005, v. 1, p. 1-20.

COUTO, R. S. Eficiência reprodutiva de vacas mestiças leiteiras criadas em sistemas de criação com e sem sombreamento, em Bujarú, Pará. Dissertação (Mestrado em ciência animal) - Universidade Federal do Pará - Belém, PA, 2013. 
CUNNINGHAM, J. G. Tratado de fisiologia veterinária. 3.ed. Guanabara Koogan, 2004. 1424p.

DALCIN, V. C. Parâmetros fisiológicos em bovinos leiteiros submetidos ao estresse térmico. Dissertação de Mestrado em Zootecnia - Produção Animal, Faculdade de Agronomia, Universidade Federal do Rio Grande do Sul, Porto Alegre, RS, Brasil. (34p.) Setembro, 2013.

DALTRO, A. et al. Efeito do estresse térmico por calor na produção de vacas leiteiras. Pesquisa Agropecuária Gaúcha. v. 26, n. 1, p. 288-311, 2020. DOI: 10.36812/ pag.2020261288-311.

DAMASCENO, J. C.; BACARI JUNIOR, F.; TARGA, L. A. Respostas comportamentais de vacas holandesas, com acesso à sombra constante ou limitada. Pesquisa Agropecuária Brasileira, Brasília, v. 34, n. 4, p. 709-715, Apr. 1999.

DIAS-FILHO. Histórico e desafios na pecuária bovina na Amazônia. / Moacyr Bernardino Dias-Filho, Monyck Jeane dos Santos Lopes. - Belém, PA: Embrapa Amazônia Oriental, 2020. (Documentos / Embrapa Amazônia Oriental, ISSN 1983-0513; 454).

FAÇANHA, D. A. E.; CHAVES, D. F.; MORAIS, J. H. G.; VASCONCELOS, A. M.; COSTA, W. P.; GUILHERMINO, M. M. Tendências metodológicas para avaliação da adaptabilidade ao ambiente tropical. Revista Brasileira de Saúde e Produção Animal, v. 14, n. 1. 2013. 91-103p.

FAO - Food and Agriculture Organization of the United Nations. FAOSTAT. Rome, 2019. Disponível em: http:// www.fao.org/faostat/en/\#data/QL. Acesso em: 23 de fevereiro de 2021.

FAO e IDF. 2013. Guia de boas práticas na produção de leite. Produção e Saúde Animal Diretrizes. 8. Roma. E-ISBN 978-92-5-006957-9

FIGUEIREDO, E. M. et al. Influência do clima na bovinocultura brasileira - Viçosa: Ed. UFV, 2014. ISSN: 1415-692X

IBGE - Instituto Brasileiro de Geografia e Estatística. Censo Agropecuário 2017. Disponível em: http://sidra.ibge.gov. br/pesquisa/censo-agropecuario/censo-agropecuario-2017. Acesso em 10 de março de 2021.

IBGE - Instituto Brasileiro de Geografia e Estatística. Pesquisa da Pecuária Municipal. Rio de Janeiro, 2019. Disponível em: https://sidra.ibge.gov.br/pesquisa/ppm/ quadros/brasil/2019. Acesso em 23 de fevereiro de 2021.

IBGE - Instituto Brasileiro de Geografia e Estatística. Pesquisa da Pecuária Municipal. Rio de Janeiro, 2019. Disponível em: https:/www.ibge.gov.br/estatisticas/ economicas/9107-producao-da-pecuaria-municipal. html edicao $=29151 \& \mathrm{t}=$ resultados. Acesso em 27 fev. 2021 .
IBGE - Instituto Brasileiro de Geografia e Estatística. Um modelo metodológico de classificação de climas (Atualizado). Diretoria de Geociências, Coordenação de Recursos Naturais e Estudos Ambientais. Rio de Janeiro, 2002. Disponível em: https://geoftp.ibge.gov.br/produtos educacionais/atlas_educacionais/atlas_geografico_escolar/ mapas_do_brasil/mapas_nacionais/informacoes_ambientais/ brasil_clima.pdf. Acesso em: 27 fev. 2021.

MELLACE, E. M. Eficiência reprodutiva de vacas mestiças leiteiras criadas em sistemas de criação com e sem sombreamento. Dissertação (Mestrado) - Escola Superior de Agricultura Luiz de Queiroz, Piracicaba, 2009.

MENDONÇA, F. Climatologia: Noções básicas e climas do Brasil / Francisco Mendonça, Inês Moresco Danni Oliveira. São Paulo : Oficina de Textos, 2007. 139-157p.

MINKA, N. S., AYO, J. O. Physiological responses of food animals to road transportation stress. African Jounal of Biotechnology, v. 9, n. 40, p. 6601-6613, 2010.

NCR. Nutrient requirements of dairy cattle/Subcommittee on Dairy Cattle Nutrition, Committee on Animal Nutrition, Board on Agriculture, National Research Council. - 7threv. ed. 2001.

ORELLANA, J. B. P.; ORELLANA, B. B. M. A.; SEGOVIA, J. F. O. Caracterização das condições cimáticas na Amazônia. In: SEGOVIA, J. F. O. (ED.). Floricultura tropical: técnicas e inovações para negócios sustentáveis na Amazônia. Brasília, DF: Embrapa, 2020. Cap. 2, p. 3.

PARANHOS DA COSTA, M. J. R. (2000). Ambiência na produção de bovinos de corte a pasto. Anais de Etologia, 18: 26-42.

PASSOS, L. H. S. A logística de transportes na Amazônia ocidental: desafios, limitações e importância para o desenvolvimento do estado de Roraima. Revista de Administração de Roraima, Ed. 3, v. 2, 4-18, $2^{\circ}$ Sem - Boa Vista, 2013

PEREIRA, I. L. et al. Cenário atual da pecuária leiteira ativa nas propriedades rurais de Presidente Figueiredo, Amazonas, Brasil. Revista Agrária Acadêmica, v. 2, n. 3, Maio/Jun. 2019.

PERISSINOTO, M. et al. Influência do ambiente na ingestão de água por vacas leiteiras. Revista Brasileira de Engenharia Agrícola e Ambiental, v. 9, n. 2, 2005. 289$294 p$.

PINHEIRO, A. da C. et al. Características anatomofisiológicas de adaptação de bovinos leiteiros ao ambiente tropical. Revista AGROTEC, v. 36, n. 1, p. 280293, 2015. https://doi.org/10.25066/agrotec.v36i1.22280

PINHEIRO, M. G. Produção de Leite em clima Tropical. 
Pesquisa \& Tecnologia, v. 9, n. 1, Jan-Jun. 2012. ISSN

ROCHA, D. T. da. et al. Cadeia produtiva do leite no Brasil: produção primária. Circular Técnica, 123. Juiz de Fora: Embrapa Gado de Leite, 2020.

SALMAN, A. K. D; PFEIFER, L. F. M. Pecuária leiteira na Amazônia. Embrapa Rondônia - Livro Técnico (INFOTECA-E), 2020. Disponível em: http://www.infoteca. cnptia.embrapa.br/infoteca/handle/doc/1126135. Acesso em: 27 fev. 2021.

SALMAN, A. K. D. et al. Espécies arbóreas nativas da Amazônia Ocidental Brasileira com potencial para arborização de pastagens / Ana Karina Dias Salman, Giovana Fiorela Zamora López, Michelliny de Matos BentesGama, Carlos Mauricio Soares de Andrade. -- Porto Velho, RO: Embrapa Rondônia, 2008.

SANTOS, M. A. S. dos. et al. Índice de modernização da pecuária leiteira no estado de Rondônia: determinantes e hierarquização. Perspectiva Econômica, v. 7, n. 2, p. 93-106, jul./dez. 2011.

SANTOS, et al. Fatores tecnológicos de modernização da pecuária leiteira no estado do Tocantins. Revista em Agronegócios e Meio Ambiente, v. 7, n. 3, p. 591-612, set./ dez. 2014.

SILVA, A. R.; SCHEWARTZ, G. Sobrevivência e crescimento inicial de espécies florestais em sistema de integração lavoura-pecuária floresta no leste da Amazônia.

Revista em Agronegócio e Meio Ambiente, v. 12, n. 1, p. 45-63, jan./mar. 2019. e-ISSN: 2176-9168.

SIMONSEN, R. C. História econômica do Brasil: 15001820 / Roberto C. Simonsen. - Brasília: Senado Federal, Conselho Editorial, 2005. 191-200p.

TAVARES, J. E.; BENEDETTI, E. Água: uso de bebedouros e sua influência na produção de bovinos em pasto. FAZU em Revista, Uberaba, n. 8, p. 152-157, 2011.

VEIGA, J. B. da. Sistemas de produção: criação de gado leiteiro na zona Bragantina / Editado por Jonas Bastos da Veiga. - Belém-PA: Embrapa Amazônia Oriental, 2006.

VILELA, D. et al. Pecuária de leite no Brasil: cenários e avanços tecnológicos. - Brasília, DF : EMBRAPA, 2016.

VILELA, R. A. et al. Respostas fisiológicas e comportamentais de vacas Holandesas mantidas em sistema adiabático evaporativo. Pesquisa Veterinária Brasileira, Rio de Janeiro, v. 33, n. 11, p. 1379-1384. 2013. 